\title{
28
}

\section{ISO Standards in Software Engineering}

\section{J. Billington}

University of South Australia, Signal Processing Research Institute, The Levels, Adelaide, S.A., 5095, Australia

\begin{abstract}
This paper introduces the work of ISO/IEC JTC1/SC7 Software Engineering. SC7 is going through a period of rapid change, with reorganisations occurring at the last 4 Plenary meetings to meet the needs of the software engineering community.
\end{abstract}

Keyword Codes: D.2; K.6.2

Keywords: Software Engineering; Software Management

\section{INTRODUCTION}

Intemational standards in software engineering will play an important role in improving the quality of software during the next decade. The initial thrust is to produce standards for the software development process in the hope that understanding the process, documenting it and then submitting it to continuous improvement will make the development of software repeatable and lead to substantial improvements in quality. A second thrust is to develop standards that directly apply to software products.

The main body entrusted with the development of international standards for information technology is Joint Technical Committee 1 (JTC1) of the International Organisation for Standardisation (ISO) and the International Electrotechnical Commission (IEC). Subcommittee seven (SC7) of JTC1 is the main committee with responsibility for software engineering (SE) standards. This committee liaises with a large number of other committees within JTC1, and other ISO and IEC Technical Committees. An important liaison is with ISO/TC176 which is responsible for the ISO 9000 series of Quality standards.

It is very important that purchasers, suppliers and educators are aware of intemational standards. This is because purchasers will be able to mandate the use of various standards with the result that suppliers who do not conform will be at a significant disadvantage, particularly in international markets. The purpose of this paper is to provide a brief summary of the activities of ISO/IEC JTC1/SC7, Software Engineering, and to promote the need to become active in the formulation and promulgation of international standards.

\section{ISO/IEC JTC1/SC7}

The Software Engineering subcommittee, SC7, is chaired by Mr. J. Coté, from Canada which also carries the administrative load. This is handled by the Standards Council of Canada, which runs the secretariat. The current secretary is Mr François Coallier from Bell Canada. Quoting from the Secretariat's Report [2], SC7's area of work comprises: 'Standardization of management techniques, processes, methods and tools necessary for the engineering, development, maintenance and support of software products.' 
Every ISO subcommittee comprises a set of member countries, normally represented by their national standards bodies, for example, the British Standards Institute in UK. Members can be active in developing international standards by contributing material and comment and by participating in meetings, in which case they are designated as ' $\mathrm{P}$ ' members. Members can also be observers, where they can obtain official subcommittee (SC N numbered) documents, but they don't participate. These members are known as 'O' members. As of June 1994, SC7 comprised 25 'P' members (including Australia, USA, Japan, UK and many other European countries), and 15 'O' members.

In ISO, standards are developed using a process of consensus, involving 5 stages: Proposal stage a new work item is prepared and voted on by 'P' members; Preparatory stage - a working draft (WD) is prepared and voted on for registration as a Committee Draft (CD); Committee stage - CD is revised to take into account member body comments and voted on for registration as a Draft International Standard (DIS); Approval stage - DIS is revised and voted on for approval as an International Standard (IS); Publication stage - IS is published. If there is insufficient support or agreement at any stage, further development and resolution of different positions need to take place, often including further balloting.

An early report on the work of SC7 appeared in IEEE Computer [1]. Since that paper was published in March 1991, major changes in the structure and work of SC7 have occurred. SC7 comprises a set of working groups (WGs) and holds a full meeting (a plenary) once a year in June. The following brief history illustrates the extent of revitalisation. SC7 was re-organised from 5 WGs into 8 WGs in June 1991, and at the June 1992 plenary, decided to disband WG5 and form two new WGs (10 and 11). In June 1993, its WG1 was merged with the new WG11 which obtained full working group status, having operated as an interim WG in its first year. At its Ottawa meeting in June 94, SC7 spawned a new WG 12 'Function Size Measurement', created two ad hoc groups (Quality Aspects of Software Systems and Software-System Relationships), totally changed the emphasis of WG9 to concentrate on software integrity, and significantly changed its WG convenors. SC7 now has 9 WGs, labelled 2 through 12, but excluding 3 and 5 . It also has a special work group for SC7 business planning, and an Advisory Group.

The working groups normally meet twice a year, but occasionally there can be more meetings, including special ad hoc or editing meetings when results are wanted quickly. A summary of each meeting is provided as minutes which are circulated as official SC7 numbered documents. Most of the inputs and outputs of the WG meetings are only published as working group documents, and can only be obtained by ' $\mathrm{P}$ ' members who register a particular individual as the member body's representative.

The SC7 secretariat now runs an electronic mail service to members (SC7_NEWS@qc.bell.ca) which greatly speeds up delivery of some SC7 documents, and provides other useful information (such as conference announcements). SC7 members are strongly encouraged to use email to progress SC7's work programme.

\section{SUMMARY OF SC7 PROJECTS}

This section provides a very brief summary of the projects undertaken in SC7's working groups. Further information can be found in [2] and the resolutions of the Ottawa Plenary, circulated by email on SC7_NEWS@qc.bell.ca (SC7_NEWS-94-54) on 23 July 1994.

\subsection{WG2: System Software Documentation}

The convenor of WG2 is Mr. K. Johnson (UK). WG2's scope covers the development of standards for the documentation of software systems. The main project has been the revision of IS 6592 'Guidelines for the Documentation of Computer-Based Application Systems', which is to be circulated as a CD. ISO TR 9294 'Guidelines for the management of Software Documentation' will be revised to ensure consistency with DIS 12207 (see WG7 below). It is proposed to fast track a British Standard 'Guidelines for the design and preparation of documentation for users of application software' through SC7. 


\subsection{WG4: Tools and Environment}

WG4 is convened by Mr. T. Vollman (USA) and has developed Committee Draft 14102 Evaluation and Selection of CASE Tools, which will be revised and distributed for 6 month DIS ballot. A new work item regarding the adoption of CASE Tools into organisations has been accepted.

\subsection{WG6: Evaluation and Metrics}

This WG, convened by Mr. M. Azuma (Japan), is developing a series of standards for software product evaluation. The first standard, ISO/IEC 9126, Software Product Evaluation - Quality Characteristics, was published in 1992 and will be revised into a 3 part standard. The series comprises a set of 7 follow-on standards (General Guide, Metrics Planning and Implementation, Developer's Guide, Buyer's Guide, Evaluator's Guide, Guide to producing Evaluation Modules and Indicators and Metrics) which are at working draft or committee draft stage. A new standard, IS 12119: Software Quality Requirements and Testing, has recently been approved and will be published shortly. A new project on measurement and rating of data processing performance is currently at the preparatory stage.

\subsection{WG7: Life Cycle Management}

WG7 is convened by Mr. J. Roberts (USA) and has developed a major standard (DIS 12207-1) on life cycle management that at the time of writing was still under DIS balloting to become an international standard. The standard provides a set of descriptions of processes that can be tailored for a two party supplier-purchaser contract. A follow-on 'Guide Book for Life Cycle Processes' technical report is currently under development. New work will cover the areas of Software Maintenance and Mock-Ups and Prototypes.

\subsection{WG8: Support of Life Cycle Processes}

Mr. D. Schultz (USA) has recently taken over as convenor of WG8, which is producing a set of standards on various life cycle processes. These include Software Configuration Management (CD $12207-2$, to be revised and circulated for DIS ballot, planned 11/94) and working drafts on Project Management, Software Quality Assurance, Verification and Validation, and Formal Review and Audits. A Life Cycle Process Overview standard is also planned once the other standards have been completed.

\subsection{WG9: Software Integrity}

WG9 was originally established to consider the mapping of standards onto a framework for software engineering standards, which was accepted for publication as a technical report. This work was convened by Richard Ivy (USA), and it has produced a draft technical report 14399, Mapping of Standards Pertinent to Software Engineering, which once published will be maintained by the secretariat. This technical report is a compendium of software engineering standards (and work in progress) produced by various standards bodies. With this work nearly completed, the WG has been refocussed to develop standards on software integrity at the systems level in collaboration with IEC TC56/WG10. It is currently temporarily convened by Mr. L. Tripp (USA).

\subsection{WG10: Software Process Assessment}

Convened by Mr. Alec Dorling (UK) since its establishment in June 1992, Working Group 10 is developing a set of draft technical reports in the area of process assessment under very tight time scales. The project is known as SPICE (Software Process Improvement and Capability dEtermination). Seven draft TR's are planned to be progressed from Working drafts to DIS by April 1995. These are: Introductory Guide, Process Assessment Guide, Process Improvement Guide, Process Capability Determination Guide, Assessor Training and Qualification Guide, Baseline Practices Guide and Assessment Instrument. 


\subsection{WG11: Software Engineering Data Definition and Representation}

At its June 1992 plenary, SC7 established interim WG11, with Mr. Peter Eirich (USA) as convenor. Its mission was to develop a set of standards for the unambiguous description of software engineering data, such as specifications and designs, and to allow these to be interchanged between different repositories and CASE tools, while preserving their meaning. In June 1993, interim WG11 was merged with WG1, which dealt with human communication of designs and descriptions (such as state event diagrams and data flow diagrams), to form a new WG11. WG1 had nearly finalised ISO/IEC 11411 on state transition diagrams and was in the process of developing a working draft, Diagram eXchange Language (DXL) for tree structured charts, when the merger occurred. It was agreed at the last Plenary that DXL would be circulated as a $\mathrm{CD}$.

The major work of WG11 over the next few years will be developing a set of standards based on the Electronics Industries Association (EIA) interim CASE Data Interchange Format (CDIF) standards. Agreement was reached that a set of 16 CDIF documents would be circulated as WG11 Working Drafts during the next 12 months.

\subsection{WG12: Functional Size Measurement}

The Ottawa Plenary in June 1994 created WG12 with Mr. H. Rehesaar (Australia) as its convenor, as a group spawned from WG6 to establish a set of practical standards for functional size measurement. They are currently working on a Function Point Analysis standard that will be circulated for $\mathrm{CD}$ ballot.

\subsection{Ad Hoc Groups}

SC7 established two adhoc groups: "Quality Aspects of Software Systems", convened by Mr. Yossi Winograd (USA) and "Software-System Relationship" convened by Dr. Raghu Singh (USA). The main purpose of the first adhoc group is to ensure consistency of the SC7 standards work with that of ISO/TC176 on software specific quality standards, such as ISO 9000.3 . The second group was formed to investigate the relationship between systems engineering and software engineering. Both groups are to report to JTC1/SC7 by February 1995.

\section{CONCLUSIONS}

ISO/IEC JTC1/SC7 has refocussed its efforts to produce standards of considerable importance to industry. The next two years will see the publication of major process and product standards. In particular, the life-cycle management standard ISO/IEC 12207 will be available for two party contracts and this will be supported by specific process standards, such as software configuration management, and a set of draft standards on process assessment. It is vital that the software industry is aware of the status of the standards and it is hoped that this paper will contribute to this objective.

\section{REFERENCES}

1 Edelstein D.V., Fujii R., Guerdat C., and Sullo P., 'Intemationalizing software engineering standards', Computer, March 1991, Vol.24, (3), pp 74-78

2 ISO/IEC JTC1/SC7, 'Secretariat's Report', June 1994, SC7 Standing Document 1, pp $1-38$ 